ISSN 1678-992X

\title{
Vigor-S, a new system for evaluating the physiological potential of maize \\ seeds
}

\author{
Danielle Otte Carrara Castan, Francisco Guilhien Gomes-Junior, Julio Marcos-Filho*
}

University of São Paulo/ESALQ - Dept. of Crop Science, C.P. 09 - 13418-900 - Piracicaba, SP - Brazil.

*Corresponding author <juliomarcos.1@usp.br>

Edited by: Lincoln Zotarelli

Received October 26, 2016

Accepted January 20, 2017
ABSTRACT: The refinement of vigor tests and the possibility of utilizing computer resources for the effective evaluation of the seed physiological potential have attracted considerable interest from research and seed technologists. The aim of this study was to evaluate the physiological potential of maize seeds using the newly-created Automated Analysis of Seed Vigor System (Vigor-S) compared with other recommended seed vigor tests; two maize hybrids were used, each represented by seven seed lots. Germination and vigor (cold test, saturated salt accelerated aging, and field seedling emergence) evaluations were conducted. For the evaluation of seed vigor with the use of seedling image analysis resources, two systems were compared: the Seed Vigor Imaging System (SVIS ${ }^{\circledR}$ ), developed by Ohio State University, USA and the Vigor-S, resulting from collaboration between USP/ESALQ and EMBRAPA (Embrapa Instrumentation). Using these two systems, three day old seedlings were scanned and the images were analyzed. Similar results for the vigor index, uniformity of development, and seedling length were obtained. The computerized image analysis of seedlings using Vigor-S has advantages with respect to accuracy, speed, and the possibility of automatic application to a worksheet. It is a consistent alternative for the evaluation of maize seed vigor, and produces information compatible with that obtained by the accelerated aging test and $S V I{ }^{\circledR}$.

Keywords: Zea mays L., image analysis, computer vision, seedling vigor

\section{Introduction}

The use of seeds with high physiological potential is indispensable for success in agricultural production, and makes a significant contribution to rapid stand establishment and the initial development of vigorous seedlings in the field (Marcos-Filho, 2016). Although various procedures are recommended for the evaluation of maize seed vigor, such as cold test, accelerated aging and seedling growth, there are still opportunities for including innovative alternatives. Computerized image analysis of seedlings is one of these alternatives, favoring standardization, precision, objectivity, and reduction in the time period necessary for performing tests (Marcos-Filho, 2010).

According to Baalbaki et al. (2009), the first consistent attempts to use image analysis in the determination of seed vigor were carried out by McCormac et al. (1990) on carrot and lettuce seeds, and by Howarth and Stanwood (1993) in lettuce and sorghum. Subsequently, Sako et al. (2001) developed a very effective automated system for evaluating lettuce seed vigor, known as the Seed Vigor Imaging System (SVIS ${ }^{\circledR}$ ). Nevertheless, one of the main difficulties found in the use of SVIS ${ }^{\circledR}$ has been the need to make adjustments in the marking of seedlings or their parts after processing the seedling images, which requires a great deal of attention from analysts so that the parts of the seedlings are precisely identified by the system and the parameters generated by the system are obtained on a consistent basis.

As a consequence, the Automated Analysis of Seed Vigor System was projected through technical-scientific cooperation between the University of São Paulo, SP, Brazil (USP/ESALQ) and EMBRAPA (Brazilian Agricultural Research Corporation) at the Embrapa Instrumentation, initially aiming to evaluate the physiological potential of maize and soybean seeds. This system follows the same principles established for the development of the SVIS ${ }^{\circledast}$, seeking to enhance the precision of analyses and reduce problems detected during the execution of SVIS ${ }^{\circledR}$.

Thus, the objective of this study was to verify the effectiveness of Vigor-S in evaluating the physiological potential of maize seed in comparison with SVIS ${ }^{\otimes}$ and other methods recommended for evaluating maize seed vigor such as accelerated aging and the cold test.

\section{Materials and Methods}

The study was carried out in Piracicaba, in the state of São Paulo, Brazil $\left(22^{\circ} 42^{\prime} 11.2^{\prime \prime} \mathrm{S}\right.$ and $47^{\circ} 37^{\prime} 56.8^{\prime \prime}$ $\mathrm{W}$, altitude $542 \mathrm{~m}$ ). Two maize hybrids were used, 20A55 and $2 \mathrm{~B} 604 \mathrm{PW}$, each represented by seven seed lots kept in cold and dry storage $\left(10^{\circ} \mathrm{C}\right.$ and $\left.30 \% \mathrm{RH}\right)$ throughout the experimental period. Three evaluations were made at quarterly intervals, for the following determinations:

Seed water content: evaluated according to the Rules for Seed Testing (MAPA, 2009) by the laboratory oven method, at $105 \pm 3{ }^{\circ} \mathrm{C}$ for $24 \mathrm{~h}$. This determination was also carried out after exposure of the seeds to accelerated aging.

Germination: evaluated in four replications of 50 seeds in rolls of paper toweling moistened with a weight of water 2.5 times the weight of the dry paper, 
at $25^{\circ} \mathrm{C}$. Counting was made at four days (germination first count) and seven days after sowing, according to the criteria established in the Rules for Seed Testing (MAPA, 2009). Results were expressed as mean percentages of normal seedlings for each lot.

Saturated salt accelerated aging (SSAA): conducted through the distribution of seed samples from each lot in a single layer on a screen suspended within a plastic box $(11 \mathrm{~cm} \times 11 \mathrm{~cm} \times 3 \mathrm{~cm})$ containing $40 \mathrm{~mL}$ of saturated $\mathrm{NaCl}$ solution, so as to provide an environment of $76 \%$ relative humidity (Jianhua and McDonald, 1996). The boxes were kept in a water jacketed accelerated aging chamber at $41{ }^{\circ} \mathrm{C}$ for $96 \mathrm{~h}$, and after that the germination test was conducted with four replications of 50 seeds for each lot. Results were expressed as mean percentages of normal seedlings for each lot.

Cold test: conducted with four replications of 50 seeds per lot, using plastic trays $(34 \mathrm{~cm} \times 23 \mathrm{~cm} \times 7$ $\mathrm{cm}$ ) containing $1 \mathrm{~kg}$ of a mixture of soil (coming from the maize growing area) and sand in the proportion of 1:3 in volume. In each tray, after the addition of the substrate, two replications of 50 seeds were distributed and covered with $1 \mathrm{~kg}$ of the same substrate (Caseiro and Marcos-Filho, 2000). The availability of water in the substrate was adjusted to $70 \%$ of its field capacity; water and substrata were previously cooled to $10{ }^{\circ} \mathrm{C}$. After distribution of the substrate, seeds, and water, each tray was placed in a transparent plastic bag to reduce evaporation, and then kept in a cold chamber at $10^{\circ} \mathrm{C}$ for seven days. After this period, each tray was transferred to a germinator at $25^{\circ} \mathrm{C}$ and the percentages of normal seedlings were registered after five days. Results were expressed as mean percentages of normal seedlings for each lot.

Field seedling emergence: four replications of 50 seeds were used, each represented by a $4 \mathrm{~m}$ long planting furrow, spaced at $40 \mathrm{~cm}$, in which seeds were distributed at a uniform distance. The depth of each furrow was around $7 \mathrm{~cm}$ and soil cover after sowing had a depth of approximately $3 \mathrm{~cm}$. Seedlings received spray irrigation according to need. The number of seedlings that emerged was recorded daily to determine the index of speed of seedling emergence index (Maguire, 1962) and, at the end of 14 days, the percentage of seedling emergence was calculated to obtain mean values per lot.

Computerized analysis of seedling images (SVIS ${ }^{\circledR}$ and Vigor-S): five replications of 20 seeds per lot of each hybrid were used, distributed in two rows in the upper third of two sheets of paper toweling and covered with a third sheet. The substrate was previously moistened with a quantity of water weighing 2.5 times the dry weight of the substrate.

For use in the Seed Vigor Imaging System (SVIS ${ }^{\circledR}$ ), the rolls containing the seeds were kept in a seed germinator at $25^{\circ} \mathrm{C}$ for three days. At the end of this period, seedling image acquisition was achieved by a custom scanning box $(60 \mathrm{~cm} \times 50 \mathrm{~cm} \times 12 \mathrm{~cm})$ computer system constructed of sheet metal and an aluminum bed on which the germinated seedlings are placed (Figure 1). The seedlings of each replication were digitalized on a scanner (HP, Scanjet 200), and fixed upside-down inside the metal box at a scanning resolution of $100 \mathrm{dpi}$. In the SVIS, the scanned seedlings were transferred from a white colored paper towel roll onto a black or navy blue cardboard paper the same size as the scanner usable area, to provide the necessary contrast for proper seedling identification by the system.

The digitalized images of seedlings were processed by the Seed Vigor Imaging System (SVIS ${ }^{\circledR}$ ), and indexes of the uniformity of the seedling development and vigor were generated, ranging from 0 to 1000, as well as the total length of the seedlings, in centimeters (Sako et al., 2001; Hoffmaster et al., 2003; Marcos-Filho et al., 2006). To obtain results using the SVIS ${ }^{\circledR}$, the length of six inches $(15.24 \mathrm{~cm})$ was established as the maximum expected for three day old maize seedlings (germination at $25^{\circ} \mathrm{C}$ ). Determination of this maximum seedling length, required by the SVIS ${ }^{\circledR}$, was based on preliminary testing of samples from lots taken from the two hybrids. The

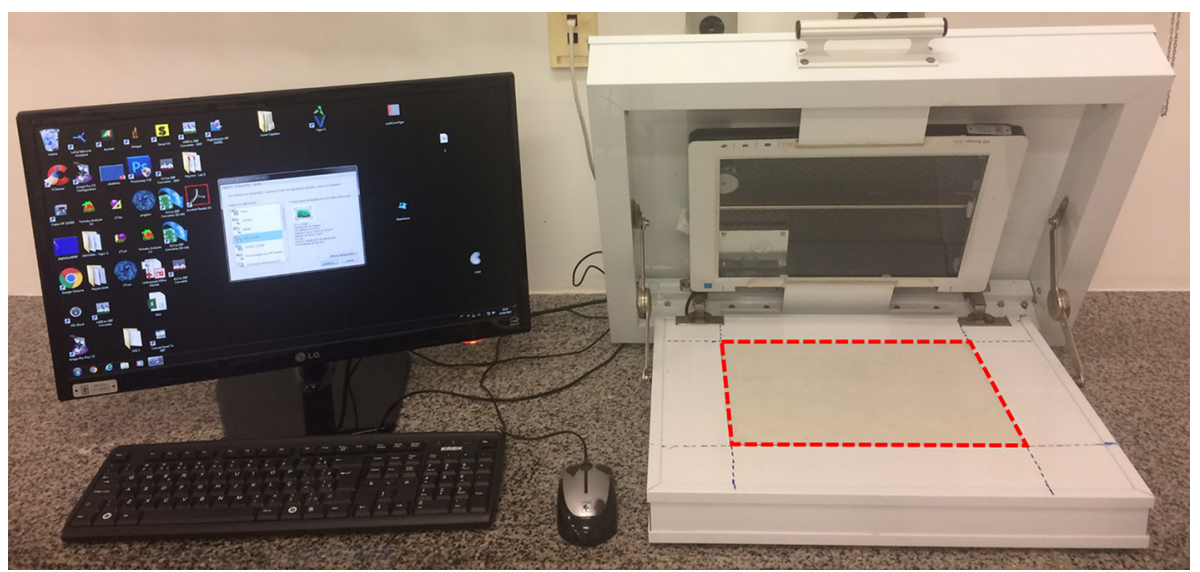

Figure 1 - Overview of the scanner (HP, Scanjet 200) installed in the inverted position inside an aluminum box (60 $\mathrm{cm} \times 50 \mathrm{~cm} \times 12 \mathrm{~cm}$ ), with a corresponding usable area of $30 \mathrm{~cm} \times 22 \mathrm{~cm}$ (dashed red) connected to the computer . 
contribution of the value of growth and uniformity to the calculation of the vigor index was $70 \%$ and $30 \%$, respectively.

In order to use the Vigor-S, after obtaining seedlings as reported above, their images were digitalized in a scanner adjusted to a resolution of $300 \mathrm{dpi}$. The automated analysis using the Vigor-S system provides for seedlings to be scanned directly onto a germination paper navy blue in color. In this analysis, the contribution of the value of growth and uniformity for calculating the vigor index was $70 \%$ and $30 \%$, respectively. For Vigor-S, the indexes of uniformity of development and vigor (variation from $0-1000$ ) and the total length of seedlings (centimeters) were obtained. The equations for calculating the vigor and uniformity of growth indexes were determined in accordance with those established by Sako et al. (2001) for the SVIS ${ }^{\circledR}$. However, for calculating the uniformity index using Vigor-S, an adaptation of the Christiansen's uniformity coefficient (Christiansen, 1942) was used according to equations 1 and 2 below:

$$
\begin{aligned}
& \text { Uniformity }=\left(1-\frac{\sum_{i=1}^{n}|X i-\bar{X}|}{n \times X}\right) \times 1000-\text { Penalty } \\
& \text { Penalty }=n_{\text {dead }} \times\left(\frac{50}{n_{\text {total }}}\right)
\end{aligned}
$$

In equation (1), $X i$ is the length of the seedling analyzed, $\bar{X}$ the mean seedling length from the seed lot analyzed, and the variable $n$ the number of seedlings comprising the image analyzed. The penalties, represented by equation (2) used for lots where ungerminated or dead seeds were present, were calculated according to the number of seeds that did not germinate, $n_{\text {dead }}$ and the total number of seedlings, $n_{\text {total }}$.

It should be noted that the same digitalized samples were evaluated by the two systems /Vigor-S and SVIS ${ }^{\circledR}$ ) for the purpose of comparing their effectiveness in a reliable manner.

\section{Statistical analysis}

Data were submitted to analysis of variance in a completely randomized design, except for data from field seedling emergence, which were analyzed according to randomized blocks. Mean values were compared by Tukey test $(p \leq 0.05)$ using the Assistat software program, version 7.7 beta.

\section{Results and Discussion}

Analyses of variance of data from germination and vigor tests for both hybrids did not show significant differences attributable to the effects of seed lots on most tests conducted, except for saturated salt accelerated aging (for the hybrid 2B604PW). The means obtained in the germination and vigor tests (germination first count, cold, accelerated aging, percentage and speed of seedling emergence) are shown in Table 1.
Table 1 - Germination (Germ.), germination first count (GFC), cold test, saturated salt accelerated aging (SSAA), percentage and speed of seedling emergence (SSE) of seven seed lots of maize, hybrids $20 \mathrm{~A} 55$ and 2B604PW. Mean of three

\begin{tabular}{|c|c|c|c|c|c|c|}
\hline \multicolumn{7}{|c|}{ Hybrid 20A55 } \\
\hline Lots & Germ. & GFC & Cold test & SSAA $96 \mathrm{~h}$ & $\begin{array}{l}\text { Seedling } \\
\text { emergence }\end{array}$ & $\begin{array}{c}\text { SSE } \\
\text { (index) }\end{array}$ \\
\hline & & & & $-\%-$ & 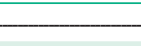 & \\
\hline L1 & 99 & 98 & 64 & 97 & 96 & 9.44 \\
\hline L2 & 99 & 99 & 62 & 98 & 93 & 8.85 \\
\hline L3 & 99 & 98 & 62 & 99 & 96 & 9.33 \\
\hline L4 & 99 & 99 & 64 & 99 & 95 & 9.28 \\
\hline L5 & 99 & 99 & 60 & 99 & 95 & 9.18 \\
\hline L6 & 99 & 99 & 60 & 99 & 95 & 9.27 \\
\hline \multirow[t]{2}{*}{$\underline{\mathrm{L7}}$} & 99 & 99 & 57 & 98 & 94 & 9.08 \\
\hline & ns & ns & ns & ns & ns & ns \\
\hline \multicolumn{2}{|c|}{ C.V. (\%) 1.75} & 1.84 & 45.13 & 1.7 & 4.44 & 5.22 \\
\hline \multicolumn{7}{|c|}{ Hybrid 2B604PW } \\
\hline \multirow[t]{2}{*}{ Lots } & Germ. & GFC & Cold test & SSAA $96 \mathrm{~h}$ & $\begin{array}{l}\text { Seedling } \\
\text { emergence }\end{array}$ & $\begin{array}{l}\text { SSE } \\
\text { (index) }\end{array}$ \\
\hline & & & & $-\%$ & 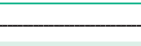 & \\
\hline L8 & 100 & 98 & 73 & $98 a b$ & 97 & 10.79 \\
\hline L9 & 100 & 99 & 76 & 99 a & 96 & 10.41 \\
\hline L10 & 98 & 98 & 79 & 99 a & 98 & 10.66 \\
\hline L12 & 99 & 99 & 77 & 98 a & 97 & 10.76 \\
\hline L13 & 98 & 98 & 77 & 99 a & 96 & 10.63 \\
\hline L14 & 99 & 98 & 74 & 99 a & 99 & 10.69 \\
\hline \multirow[t]{2}{*}{$\underline{L} 15$} & 98 & 97 & 76 & $94 \mathrm{~b}$ & 95 & 10.47 \\
\hline & ns & ns & ns & & ns & ns \\
\hline C.V. (\%) & 1.71 & 2.25 & 12.54 & 2.26 & 2.48 & 3.94 \\
\hline
\end{tabular}
experimental times.

Lowercase letter $=$ means comparison within each column for each evaluation (Tukey test, $p \leq 0.05$ ); ns = non-significant; C.V. = coefficient of variation.

It was found that the lots of the two hybrids had similar germination percentages, which were above $85 \%$, and narrow vigor differences. Seed water contents at the beginning of the evaluations ranged from $8 \%$ to $9 \%$; after, saturated salt accelerated aging seed water contents were from $11 \%$ to $12 \%$. Variations of up to two percentage points after accelerated aging are considered tolerable as regards reliability of results (Baalbaki et al., 2009).

Analyses of variance of the data obtained in evaluations carried out in the SVIS ${ }^{\circledR}$ and Vigor-S showed differences between seed lots of the hybrid 2B604PW, but the same was not found for the hybrid 20A55 seed lots (Table 2).

Information in relation to the vigor index, to uniformity of development, and to seedling length with the use of Vigor-S was similar to that provided by the SVIS $^{\circledR}$, in which the lots of hybrid 20A55 did not differ in relation to vigor, or the other tests used. Vigor tests that evaluate seedling performance (e.g., shoot growth, primary root growth, seedling dry weight) are based on the fact that more vigorous seeds give rise to more developed seedlings, reflecting the effectiveness of the 
Table 2 - Vigor index (Vig.), uniformity of seedling development index (Unif.) and length (Length) of three day old seedlings of seven seed lots of maize, hybrids 20A55 and 2B604PW, evaluated by Seed Vigor Imaging System (SVIS $\left.{ }^{\circledR}\right)$ and Automated Analysis of Seed Vigor System (Vigor-S). Mean of three experimental times.

\begin{tabular}{|c|c|c|c|c|c|c|}
\hline \multicolumn{7}{|c|}{ Hybrid 20A55 } \\
\hline \multirow{2}{*}{ Lots } & \multicolumn{3}{|c|}{ SVIS ${ }^{\circledast}$} & \multicolumn{3}{|c|}{ Vigor-S } \\
\hline & Vig. & Unif. & Length & Vig. & Unif. & Length \\
\hline & \multicolumn{2}{|c|}{$\longrightarrow$ index -} & $\mathrm{cm}$ & \multicolumn{2}{|c|}{- index -} & $\mathrm{cm}$ \\
\hline L1 & 781 & 899 & 10.91 & 698 & 673 & 11.66 \\
\hline L2 & 754 & 898 & 10.47 & 725 & 726 & 11.40 \\
\hline L3 & 738 & 896 & 10.17 & 699 & 690 & 11.21 \\
\hline L4 & 746 & 901 & 10.27 & 702 & 734 & 10.98 \\
\hline L5 & 720 & 902 & 9.77 & 687 & 733 & 10.74 \\
\hline L6 & 761 & 902 & 10.73 & 714 & 714 & 11.59 \\
\hline \multirow[t]{2}{*}{$\mathrm{L} 7$} & 747 & 902 & 10.38 & 720 & 723 & 11.47 \\
\hline & ns & ns & $\mathrm{ns}$ & ns & ns & ns \\
\hline C.V. (\%) & 9.31 & 1.54 & 14.46 & 9.02 & 9.24 & 13.66 \\
\hline \multicolumn{7}{|c|}{ Hybrid 2B604PW } \\
\hline \multirow{3}{*}{ Lots } & \multicolumn{3}{|c|}{ SVIS ${ }^{\circledR}$} & \multicolumn{3}{|c|}{ Vigor-S } \\
\hline & Vig. & Unif. & Length & Vig. & Unif. & Length \\
\hline & \multicolumn{2}{|c|}{- index -} & $\mathrm{cm}$ & \multicolumn{2}{|c|}{ - index } & $\mathrm{cm}$ \\
\hline L8 & $795 a$ & 902 & $11.38 \mathrm{a}$ & $743 a$ & 676 & 12.22 \\
\hline L9 & $760 a b$ & 902 & $10.61 \mathrm{ab}$ & $690 a b$ & 700 & 10.92 \\
\hline L10 & 726 b & 896 & $9.87 \mathrm{~b}$ & $628 b$ & 607 & 10.22 \\
\hline L12 & $721 b$ & 899 & $9.76 b$ & $699 a b$ & 708 & 11.15 \\
\hline L13 & $752 a b$ & 896 & $10.33 a b$ & 745 a & 759 & 11.87 \\
\hline L14 & $713 b$ & 892 & $9.66 \mathrm{~b}$ & $714 a b$ & 712 & 11.37 \\
\hline L15 & $740 a b$ & 882 & $10.01 \mathrm{ab}$ & $708 a b$ & 695 & 11.35 \\
\hline & & ns & & & ns & ns \\
\hline C.V. (\%) & 6.57 & 1.82 & 10.45 & 10.73 & 14.11 & 13.02 \\
\hline
\end{tabular}

Lowercase letter $=$ means comparison within each column for each evaluation (Tukey test, $p \leq 0.05$ ); ns = non-significant; C.V. = coefficient of variation.

action of repair mechanisms, mobilization of reserves, and synthesis of new tissues during germination (Marcos-Filho, 2010).

In any case, results obtained in the different tests conducted here showed that seed lots of high physiological potential were evaluated. All the tests conducted detected this performance, such that the results obtained were consistent, also in relation to seedling emergence in the field; this is one of the basic requirements for characterizing the effectiveness of a vigor test.

The studies on automated analysis of seedling images have basically compared results obtained from SVIS ${ }^{\circledast}$ with those from tests usually accepted for seed vigor evaluation, as observed with melon (Marcos-Filho et al., 2006), soybean (Marcos-Filho et al., 2009), cucumber (Chiquito et al., 2012), sweet corn (Alvarenga et al., 2012), and wheat (Silva et al., 2012), among other crops.

In this respect, the development of image analysis systems projected for seed germination and for vigor tests shows their potential in the study of seed performance, with the perspective of combining traditional methods for the evaluation of seed quality with those that provide more precise biomorphological data (Dell'Aquila, 2009).
Although marked differences in the performance of the seed lots of the two hybrids were not found, according to the information provided by the two systems of seedling image analysis, the aim of this study was the identification of the effectiveness of the new Vigor-S system in evaluating the physiological potential of maize seeds. It should be emphasized that this system saves the time when obtaining digitalized images because it was programmed to analyze the seedling images already digitalized on blue-colored germination paper.

In contrast, in SVIS ${ }^{\circledR}$ analyses, it is necessary to transfer seedlings from the paper towel of germination (white or light brown color) to another of dark coloring (generally black or navy blue) to obtain contrast and adequate image processing. In addition, in the SVIS ${ }^{\circledR}$ system, there are problems in correctly identifying parts of the seedlings (for example, separation of the root system and hypocotyl in various species) for automated processing of the data, especially seedling length.

The development of technologies with an integration of new algorithms and hardware architecture for data extraction, such as digital images of seeds and seedlings, and the numerical data (dimensional calculations), contribute to the improvement of information technology that is responsible mainly for the acquisition, registration, and organization of the results (Dell'Aquila, 2009). In this respect, in addition to minimizing the interference of the analyst to make corrections of nondemarcated parts of the seedlings and reduce the time of analysis, the Vigor-S system showed the possibility for better utilization of the results obtained from the same evaluation, automatically supplying the lengths of the primary root, the shoot, and the seedling in total, as shown in Figures 2A and B. Consequently, it is a more detailed and precise evaluation, which, among others, is an important argument towards the acceptance of the system by seed analysts (McDonald, 1975; Hampton, 1993; Marcos-Filho, 1998). The SVIS showed significant higher precision when compared with manual measurements of seedlings, as reported by Hoffmaster et al. (2003). As the Vigor-S follows the same principle of SVIS the higher precision in comparison to manual measurements is naturally expected.

Although the lots tested here showed high vigor, it was possible to identify a tendency of superior vigor of seeds from lot 8 of the hybrid 2B604PW, exhibited both in the results of the Vigor-S (vigor index) and of the SVIS ${ }^{\circledR}$ (vigor index and seedling length), as shown in Table 2 . The small variations identified when comparing results from both systems for the seed lots of this hybrid are normal in lots of high seed physiological potential and they did not affect the effectiveness of either system.

It is also noteworthy that in the Vigor-S, greater image resolution (300 dpi) is fundamental for obtaining more precise results; in the SVIS ${ }^{\circledR}$, images are generated with a resolution of 100 dpi. Moreover, in the Vigor-S, 


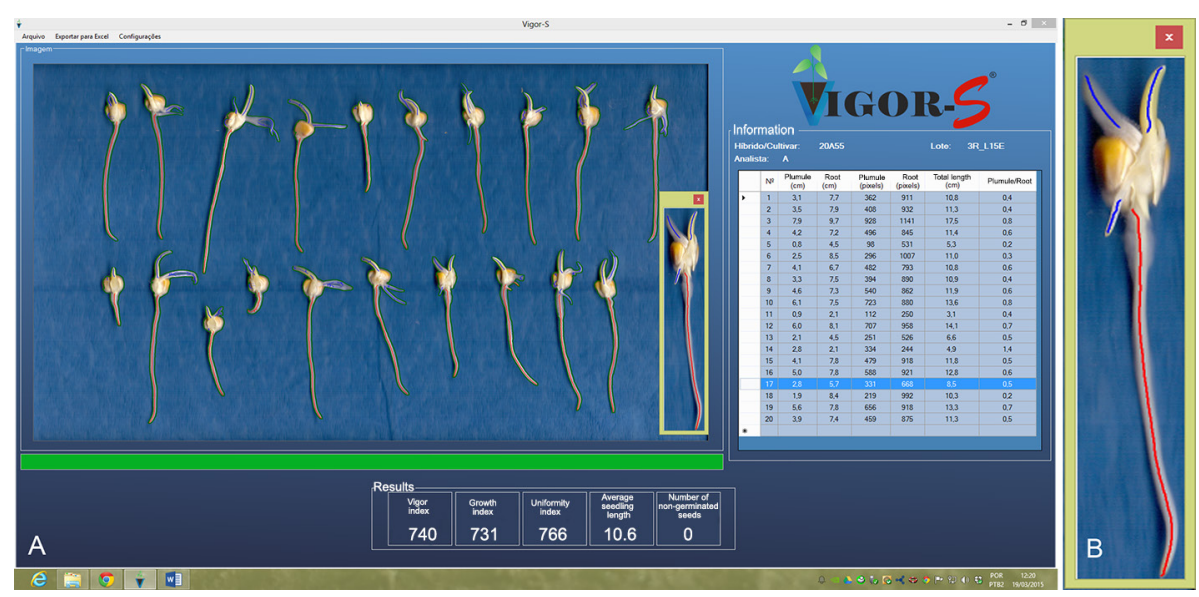

Figure 2 - Automated Analysis of Seed Vigor System - Vigor-S: analysis window showing a sample of scanned corn seedlings and processed by the software with results of vigor index (740), growth index (731), uniformity index (766), average seedling length $(10.6 \mathrm{~cm})$, number of non-germinated seeds $(0)$ and table with the primary root length and total length of each seedling $(A)$; detail of the seedling number 17 showing the primary root (red) and secondary roots and plumule (blue) (B).

the results of analyses (vigor, uniformity, and seedling length indexes) can be exported to extensions of Excel software, allowing for better organization of the information obtained and greater ease in subsequent interpretation of the results by seed analysts. To perform the Vigor-S analyses, in addition to the specific software to process the images it is necessary to fix in place a custom scanner upside-down inside an aluminum box as described by Marcos-Filho et al. (2009) and a computer (Intel Core $\geq$ i5, 8 GB RAM) operated by a Windows 8.1 system.

The indexes of uniformity of seedling development in both hybrids and systems indicated that the lots consisted of seedlings of uniform development. This uniformity index represents extremely important information because the uniformity of seedling development can affect stand establishment, since seed vigor is directly related to the initial growth of maize seedlings. In addition, uneven seedling emergence can lead to delays in development and variations in plant growth at various phenological stages, which also affect plant characteristics related to harvest (Marcos-Filho, 2016).

The Vigor-S was sensitive to detect differences in seed lot vigor, in the event of differences, giving rise to results comparable to those of tests traditionally recommended for the evaluation of maize seed vigor. The use of this system for the evaluation of seed's physiological potential represents a promising alternative and an advance in research. One important additional advantage is that the software system of the Vigor-S is free for general use by private seed companies, seed laboratories and for academic purposes.

Thus, the results of this study show that the use of the Vigor-S, a new technology proposed to enhance the procedures used in the evaluation of seed vigor based on seedling performance, favors standardization, preci- sion, objectivity, and reduction in time to reliably obtain results in seed quality control programs adopted by seed companies.

\section{Conclusion}

The use of computerized image analysis of seedlings through the Vigor-S is an effective alternative for evaluating maize seed vigor, and the development of this system for use in seeds of other species represents an important initiative for enhancing the evaluation of the physiological potential of seed.

\section{Acknowledgements}

The São Paulo Research Foundation - FAPESP (Proc. \#2006/57900-0 and 2013/11132-5) and Brazilian National Council for Scientific and Technological Development (CNPq) for providing financial support for this research.

\section{References}

Alvarenga, R.O.; Marcos-Filho, J.; Gomes-Junior, F.G. 2012. Evaluation of supersweet corn seed vigor using an automated computer imaging system. Revista Brasileira de Sementes 34: 488-494 (in Portuguese, with abstract in English).

Baalbaki, R.; Elias, S.; Marcos-Filho, J.; McDonald. M.B. 2009. Seed Vigor Testing Handbook. Association of Official Seed Analysts, Washington, DC, USA.

Caseiro, R.F.; Marcos-Filho, J. 2000. Alternative methods of the cold test for evaluation of corn seed vigor. Scientia Agricola 57: 459-466 (in Portuguese, with abstract in English).

Chiquito, A.A.; Gomes-Junior, F.G.; Marcos-Filho, J. 2012. Assessment of physiological potential of cucumber seeds using the Seed Vigor Imaging System ${ }^{\circledR}$. Revista Brasileira de Sementes 34: 255-263. 
Christiansen, J.E. 1942. Irrigation by Sprinkling. University of California, Berkeley, CA, USA. (California Agriculture Experiment Station Bulletin, 670).

Dell'Aquila, A. 2009. Digital imaging information technology applied to seed germination testing: a review. Agronomy for Sustainable Development 29: 213-221.

Hampton, J. 1993. The ISTA perspective of seed vigor testing. Journal of Seed Technology 17: 105-109.

Hoffmaster, A.L.; Fujimura, K.; McDonald, M.B.; Bennett, M.A. 2003. An automated system for vigour testing three-day-old soybean seedlings. Seed Science and Technology 31: 701-713.

Howarth, M.S.; Stanwood, P.C. 1993. Measurement of seedling growth rate by machine vision. Transactions of the American Society of Agricultural Engineering 36: 959-963.

Jianhua, Z.; McDonald, M.B. 1996. The satured salt accelerated aging test for small-seeded crops. Seed Science and Technology 25: 123-131.

Maguire, J.D. 1962. Speed of germination aid in selection and evaluation for seedling emergence and vigour. Crop Science 2: $176-177$.

Marcos-Filho, J. 1998. New approaches to seed vigor testing. Scientia Agricola 55: 27-33.

Marcos-Filho, J. 2010. System computerized analysis of seedling images (SVIS ${ }^{\circledR}$ ) for evaluation of seed vigor. Revista Brasileira de Sementes 20: 40-44 (in Portuguese, with abstract in English).

Marcos-Filho, J. 2016. Seed Physiology of Cultivated Plants. ABRATES, Londrina, PR, Brazil.
Marcos-Filho, J.; Bennett, M.A.; Evans, A.S.; Grassbaugh, E.M. 2006. Assessment of melon seed vigour by an automated computer imaging system compared to traditional procedures. Seed Science and Technology 34: 507-519.

Marcos-Filho, J.; Kikuti, A.L.P.; Lima, L.B. 2009. Methods to evaluate soybean seed vigor, including computerized image analysis. Revista Brasileira de Sementes 31: 102-112 (in Portuguese, with abstract in English).

McCormac, A.C.; Keffe, P.D.; Draper, R.S. 1990. Automated vigour testing of field vegetables using image analysis. Seed Science and Technology 18: 103-112.

McDonald, M.B. 1975. A review and evaluation of seed vigor tests. Proceedings of the Association of Official Seed Analysts 65: 109-139.

Ministério da Agricultura, Pecuária e Abastecimento [MAPA]. 2009. Rules for Seed Testing = Regras para Análise de Sementes. MAPA, Brasília, DF, Brazil (in Portuguese).

Sako, Y.; McDonald, M.B.; Fujimura, K.; Evans, A.F.; Bennett, M.A. 2001. A system for automated seed vigor assessment. Seed Science and Technology 29: 625-636.

Silva, V.N.; Gomes-Junior, F.G.; Cicero, S.M. 2012. Computerized imaging analysis of seedlings for assessment of physiological potential of wheat seeds. Revista Brasileira de Sementes 34: 589-596. 